\title{
Cytokines and chemokines multiplex analysis in patients with low disease activity rheumatoid arthritis
}

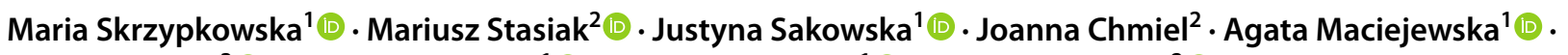

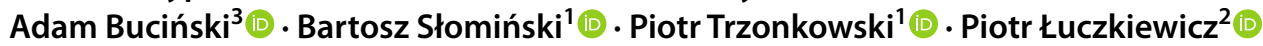

Received: 10 December 2021 / Accepted: 3 February 2022 / Published online: 18 February 2022

(c) The Author(s) 2022

\begin{abstract}
Rheumatoid arthritis is a severe chronic autoimmune disorder that results from pathological activation of immune cells and altered cytokine/chemokine network. The aim of our study was to evaluate concentrations of chosen cytokines and chemokines in blood sera and synovial fluid samples isolated from low disease activity rheumatoid arthritis (RA) patients and osteoarthritis (OA) sufferers. Blood sera and synovial fluid samples have been obtained from 24 OA and 14 RA patients. Cytokines/chemokines levels have been determined using a Milliplex ${ }^{\circledR}$ Map 38-plex human cytokine/chemokine magnetic bead-based panel (Merck Millipore, Germany) and Luminex ${ }^{\circledR}$ MAGPIX ${ }^{\circledR}$ platform (Luminex USA). Low disease activity RA patients showed altered concentration of numerous cytokine/chemokine when compared to OA controls-they were characterized by, inter alia, increased: eotaxin/CCL11 $(p=0.037)$, GRO/CXCL1 $(p=0.037)$, IL-2 $(p=0.013)$, IL-4 $(p=0.017)$, IL-7 ( $p=0.003)$, IL-8 $(p=0.0007)$ and GM-CSF $(p=0.037)$ serum levels, whilst MDC/CCL22 concentration was decreased in this group $(p=0.034)$. Eotaxin/CCL11 $(p=0.001)$, GRO/CXCL1 $(p=0.041), \mathrm{IL}-10(p=0.003)$, GM-CSF $(p=0.01)$, IL-1RA $(p=0.0005)$ and VEGF $(p=0.01)$ concentrations in synovial fluid of RA females were also increased. Even with low disease activity score, RA patients exhibited increased concentrations of cytokines with pro- and anti-inflammatory activities, as well as numerous chemokines, growth factors and regulators of angiogenesis. Surprisingly, RA subjects also shown decreased concentration of CCL22 chemokine. The attempt to restore cytokine balance and tolerogenic environment is ineffective in RA sufferers even with good disease management. Distinguished factors could serve as possible indicators of disease progression even in low disease activity patients.
\end{abstract}

Keywords Rheumatoid arthritis · Osteoarthritis · IL-2 · Eotaxin/CCL11 · MDC/CCL22 · GM-CSF · IL-10 · IL-1RA

Maria Skrzypkowska and Mariusz Stasiak have contributed equally to this work.

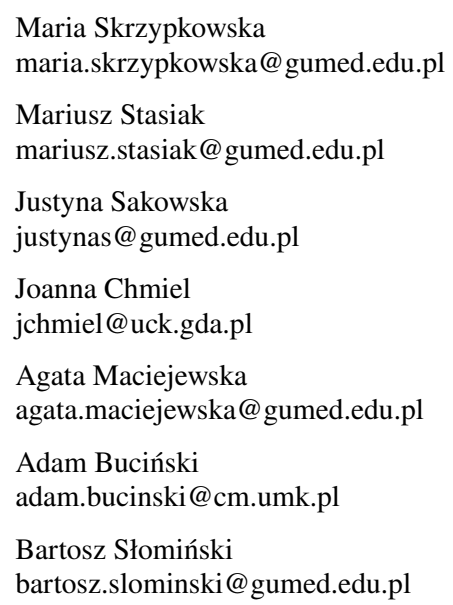

\author{
Piotr Trzonkowski \\ ptrzon@gumed.edu.pl \\ Piotr Łuczkiewicz \\ piotr.luczkiewicz@gumed.edu.pl \\ 1 Department of Medical Immunology, Faculty of Medicine, \\ Medical University of Gdańsk, Dębinki 1, 80-210 Gdańsk, \\ Poland \\ 2 Second Clinic of Orthopaedics and Kinetic Organ \\ Traumatology, Faculty of Medicine, Medical University \\ of Gdańsk, Gdańsk, Poland \\ 3 Department of Biopharmacy, Nicolaus Copernicus \\ University in Toruń, Collegium Medicum in Bydgoszcz, \\ Bydgoszcz, Poland
}




\section{Introduction}

Rheumatoid arthritis (RA) is a severe chronic autoimmune disorder that is believed to affect approximately $1 \%$ of world's population. It develops as a consequence of lack of proper inflammation resolution that lasts throughout patients' lifetime [1]. Despite the exact cause of RA being still enigmatic, it has been acknowledged that genetic factors play pivotal role in RA onset and progression. Specific and non-specific leukocytes that migrate into joints interact with synovial tissue-resident cells as well as each other, thus creating continual highly destructive synovitis $[2,3]$. This sophisticated communication between cells is heavily dependent on cytokines and chemokines. Numerous cytokines have been indicated as playing pivotal role in RA including: TNF (tumor necrosis factor), IL-1 (interleukin 1), IL-6 (interleukin 6), or IL-12 (interleukin 12) to name just a few [4]. Cytokines affect: phenotype, migration, activity and survival of cells in joints and lymphoid tissues [5] and their secretion leads to induction of different pathways and expression of various genes resulting in tissue destruction. The irreversible joint injury, mobility attenuation and disability then follow [4]. The unraveling of complex cytokine network is hindered by the dependence of their physiological effects on the stage of RA or tissue microenvironment. The disease mainly damages synovial membranes, cartilages and bones, but it also causes systemic threat by putting distress on other organs and tissues, as well [1]. RA takes a toll on cardiovascular system, psychological health or risk of cancer development. Despite successful TNF- or IL-6-targeted biological therapies, the frequency of refractory RA creates growing need to better understand cytokine hierarchy and seek for additional cytokine-focused therapeutic approaches [5].

Osteoarthritis (OA) is the most frequent chronic joint disease [6] and the most common reason for total hip and knee replacement. It is characterized by progressive degeneration of articular cartilage and increase in bone density. OA patients suffer from painful joints, functional impairment and disability [7]. With rather enigmatic etiology, OA was first recognized as a non-inflammatory joint dysfunction induced by mechanical stress or age-related degenerations [8]. However, recent studies suggested revision of OA to a low-grade chronic inflammation within leukocyte-infiltrated synovial tissue [9].

Bahlas et al. have proven Luminex technology to be useful tool to evaluate: cytokines, chemokines and growth factors in blood sera samples of RA sufferers [10]. The purpose of our analysis was to compare concentrations of these factors in blood sera as well as synovial fluid samples isolated from low disease activity RA and OA sufferers.

\section{Materials and methods}

\section{Patients}

Twenty-four patients diagnosed with OA and fourteen individuals with recognized RA have been included into our study. All participants have fulfilled American College of Rheumatology (ACR) criteria for RA [11] and OA [12] and have been scheduled to undergo arthroplasty of knee joint in the 2nd Division of Orthopaedics and Kinetic Organ Traumatology of University Clinical Centre in Gdańsk. Information received from each patient included: age, smoking history, body mass index (BMI), history of: hypertension, diabetes, cancer, cardiovascular diseases, autoimmune diseases, infectious diseases and previous surgical procedures and current medication. The inclusion criteria were as follows: age between 18 and 79 years, severity of knee OA in Kellgren-Lawrence score of 4, Disease Activity Score $28 \leq 3.2$ in RA group and agreement to participate in the study. The exclusion criteria were as follows: patient affected by autoimmune diseases other than RA, intraarticular steroid injection in the last 6 month before surgery, and biological treatment in patient with RA. Written informed consent was obtained from all participants. The study was approved by the Ethics Committee of Medical University of Gdańsk (consent no NKBBN/642/2018 received on December 10, 2018) and our investigation was carried out in accordance with the Code of 8 Ethics of the World Medical Association (Declaration of Helsinki) for experiments on human subjects.

\section{Samples collection and preparation}

Venous blood was collected into clot activator-containing tubes and allowed to clot for 30 min followed by centrifugation for $15 \mathrm{~min}$ at $1000 \mathrm{~g}$. Aliquoted serum samples were stored at $-80{ }^{\circ} \mathrm{C}$ for further analyses. Synovial fluid was collected into sterile tubes by joint puncture during the arthroplasty of knee joint procedure-sample was obtained into sterile syringe through small $1-2 \mathrm{~cm}$ longitudinal midaxial incision made approximately $2-4 \mathrm{~cm}$ above superior pole of patella. Samples of synovial fluid were centrifuged for $10 \mathrm{~min}$ at $300 \mathrm{~g}$ to remove debris and stored at $-80{ }^{\circ} \mathrm{C}$ until needed.

\section{Determination of cytokines and chemokines}

Serum and synovial fluid cytokines and chemokines concentrations have been determined using a Milliplex® Map human cytokine/chemokine magnetic bead-based panel (Merck Millipore, Germany) according to the manufacturer's instructions. Chosen factors have been analysed on 
the Luminex ${ }^{\circledR}$ MAGPIX® platform (Luminex USA). The 38-plex assay has allowed us to evaluate the following factors: interleukin $1 \alpha(\mathrm{IL}-1 \alpha)$, interleukin $1 \beta$ (IL-1 $\beta$ ), interleukin 2 (IL-2), interleukin 3 (IL-3), interleukin 5 (IL-5), interleukin 7 (IL-7), interleukin 8 (IL-8), interleukin 9 (IL-9), interleukin 12p40 (IL-12p40), interleukin 12p70 (IL-12p70), interleukin 15 (IL-15), interleukin 17A (IL-17A), epidermal growth factor (EGF), fibroblast growth factor 2 (FGF-2), transforming growth factor $\alpha$ (TGF- $\alpha)$, granulocyte-colony-stimulating factor (G-CSF), eotaxin/CCL11, FMS-like tyrosine kinase 3 ligand (Flt-3L), granulocyte-macrophage colony-stimulating factor (GM-CSF), fractalkine/CX3CL1, interferon $\alpha 2$ (IFN- $\alpha 2)$, interferon $\gamma$ (IFN- $\gamma$ ), growth-regulated alpha protein (GRO)/CXCL1, monocyte-chemotactic protein 3 (MCP3)/CCL7, macrophage-derived chemokine (MDC)/CCL22, soluble CD40 ligand (sCD40L), inducible protein 10 (IP-10)/CXCL10, monocyte-chemotactic protein 1 (MCP-1)/CCL2, macrophage inflammatory protein-1 $\alpha$ $(\mathrm{MIP}-1 \alpha) / C C L 3$, macrophage inflammatory protein- $1 \beta$ (MIP-1ß)/CCL4, tumor necrosis factor $\alpha$ (TNF- $\alpha$ ), tumor necrosis factor $\beta$ (TNF- $\beta$ ) and vascular endothelial growth factor (VEGF). Simultaneously, we have evaluated the following anti-inflammatory factors: interleukin 1 receptor antagonist (IL-1RA), interleukin 4 (IL-4), interleukin 6 (IL6), interleukin 10 (IL-10) and interleukin 13 (IL-13).

\section{Statistics}

Cytokines and chemokines detected in less than $50 \%$ of samples have been excluded from analysis. The results were analysed using the Statistica, version 12.0 (StatSoft Inc, USA). Due to small sample size, variables have been presented as median with minimum - maximum and evaluated using the Mann-Whitney $U$ test. Fisher's exact test was applied for dichotomous variables concerning clinical characteristics of participants. Values of $p<0.05$ were considered statistically significant.

\section{Results}

\section{Clinical characteristics of analysed groups}

OA group was older ( 65 vs 50; $p=0.0006)$ and had higher BMI values ( 30 vs $24.5 ; p=0.00001$ ) when compared to RA subjects did not reach statistical significance $(p=0.068$ and 0.069 respectively). OA group developed arterial hypertension $(p=0.0003)$ and hyperlipidemia $(p=0.04)$ and, consequently, were treated with $\beta$ blockers $(p=0.004)$ and angiotensin-converting enzyme inhibitors (ACEI) $(p=0.004)$ more frequently than RA sufferers. The majority of RA patients were treated disease-modifying anti-rheumatic drugs (DMARDs) $(p=0.00004)$ and steroids $(p=0.00001)$ (Table 1).

\section{Cytokines and chemokines blood serum levels}

Among detected serum-derived factors: TGF- $\alpha(p=0.29)$, IFN- $\gamma(p=0.10)$, sCD40L $(p=0.79)$, IL-1RA $(p=0.17)$, IP-10/CXCL10 $(p=0.22)$, MCP-1/CCL2 $(p=0.26)$, and $\mathrm{TNF} \alpha(p=0.37)$ have exhibited similar levels (Table 2$)$.

The RA group has been characterized by higher serum levels of the following proteins when compared to OA sufferers: EGF $(182.5,31.6-562.6$ vs $113.0,39.0-292.7$; $p=0.031)$ FGF-2 (77.0, 23.3-154.5 vs 39.8, 15.7-101.8; $p=0.017)$, eotaxin/CCL11 (138.6, 80.4-258.0 vs 110.7, $30.2-161.6 ; p=0.037)$, G-CSF $(42.0,9.5-164.5$ vs 18.3 , $0.0-95.1 ; p=0.014)$ GM-CSF $(10.2,4.7-17.7$ vs 6.6 , $3.8-11.2 ; p=0.037)$, fractalkine/CX3CL1 (43.3, 7.9-240.7 vs $11.0,0.0-114.2 .0 ; p=0.002), \mathrm{IFN}-\alpha 2(22.2,0.0-53.2$ vs $8.7,0.0-25.0 ; p=0.002)$, GRO/CXCL1 $(1.5,0.0-4.4$ vs $1.07,0.55-2.82 ; p=0.01)$, IL-2 $(1.36,0.0-5.1$ vs 0.1 , $0.0-1.7 ; p=0.013)$, IL-4 (16.2, 2.4-63.5 vs 8.7, 0.0-29.7; $p=0.017)$, IL-7 (6.0, 1.9-15.1 vs 3.3, 0.0-7.8; $p=0.003)$, IL-8 (18.3, 7.9-49.3 vs 9.6, 3.5-20.5; $p=0.0007)$, MIP-1- $\alpha /$ CCL3 (5.9, 0.0-16.9 vs 3.2, 0.0-6.5; $p=0.001)$, MIP-1 $\beta /$ CCL4 $(41.3,8.9-74.4$ vs $28.9,0.0-52.4 ; p=0.010)$ and

Table 1 Characteristics of osteoarthritis and rheumatoid arthritis patients

\begin{tabular}{llll}
\hline Characteristic & OA [24] & RA [14] & $p$ \\
\hline Gender (f/m) & $19 / 5$ & $12 / 2$ & 0.48 \\
Age (years) & $65(56-74)$ & $50(39-71)$ & $0.0006^{*}$ \\
BMI $\left(\mathrm{kg} / \mathrm{m}^{2}\right)$ & $30(24-41)$ & $24.5(19-32)$ & $0.00001^{*}$ \\
Smoking $(n)$ & 5 & 2 & 0.48 \\
Osteoporosis $(n)$ & 3 & 4 & 0.22 \\
Diabetes $(n)$ & 6 & 1 & 0.17 \\
AH $(n)$ & 20 & 3 & $0.0003^{*}$ \\
Hypothyroidism $(n)$ & 7 & 3 & 0.45 \\
Hyperlipidemia $(n)$ & 9 & 1 & $0.04^{*}$ \\
NSAIDs $(n)$ & 6 & 3 & 0.61 \\
DMARDs $(n)$ & 0 & 9 & $0.00004^{*}$ \\
Steroids $(n)$ & 1 & 11 & $0.00001^{*}$ \\
$\beta$ blockers $(n)$ & 14 & 2 & $0.004^{*}$ \\
ACEI $(n)$ & 14 & 2 & $0.004^{*}$ \\
ARBs $(n)$ & 3 & 0 & 0.19 \\
Diuretics $(n)$ & 7 & 1 & 0.09 \\
\hline
\end{tabular}

Age and BMI are presented as median and minimal-maximal values; abbreviations: $n$ number of subjects, $A C E I$ angiotensin-convertingenzyme inhibitors, $A H$ arterial hypertension, $A R B S$ angiotensin II receptor blockers, $B M I$ body mass index, DMARDs disease-modifying anti-rheumatic drugs, NSAIDs non-steroidal anti-inflammatory drugs; $p$ indicates significance between analysed groups; statistically significant differences $(p<0.05)$ between the groups have been highlighted and marked with “*” 
Table 2 Comparable cytokine and chemokine serum levels in in patients with established osteoarthritis and rheumatoid arthritis

\begin{tabular}{|c|c|c|c|c|c|c|c|}
\hline \multirow[t]{2}{*}{ Factor } & \multicolumn{3}{|l|}{$\mathrm{OA}$} & \multicolumn{3}{|l|}{ RA } & \multirow[t]{2}{*}{$p$} \\
\hline & Median & Min-max & $95 \% \mathrm{CI}$ & Median & Min-max & $95 \% \mathrm{CI}$ & \\
\hline TGF- $\alpha(\mathrm{pg} / \mathrm{ml})$ & 5.31 & $1.65-19.34$ & $3.6-6.5$ & 7.1 & $3.4-24.8$ & $4.0-8.8$ & 0.29 \\
\hline IFN- $\gamma(\mathrm{pg} / \mathrm{ml})$ & 3.2 & $0.0-44.0$ & $7.2-13.1$ & 7.9 & $0.0-14.8$ & $3.2-7.0$ & 0.10 \\
\hline sCD40L (pg/ml) & 8.3 & $2.1-16.1$ & $2.7-4.9$ & 6.2 & $2.1-17.9$ & $3.9-9.0$ & 0.79 \\
\hline IL-1RA (pg/ml) & 12.3 & $0.0-58.8$ & $12.6-23.1$ & 23.7 & $0.0-82.3$ & $16.7-38.3$ & 0.17 \\
\hline IP-10/CXCL10(pg/ml) & 177.1 & $68.1-388.8$ & $50.3-92.0$ & 206.1 & $84.2-415.3$ & $73.2-162.7$ & 0.22 \\
\hline MCP-1/CCL2 (pg/ml) & 485.5 & $305.6-716.5$ & $84.9-153.2$ & 574.4 & $317.9-840.6$ & $119.1-264.7$ & 0.26 \\
\hline $\mathrm{TNF} \alpha(\mathrm{pg} / \mathrm{ml})$ & 23.8 & $16.0-38.9$ & $4.7-8.6$ & 25.2 & $13.4-36.0$ & $5.3-11.7$ & 0.37 \\
\hline
\end{tabular}

Statistical evaluation of differences was performed using Mann-Whitney $U$ test; $p$ indicates significance between analysed groups
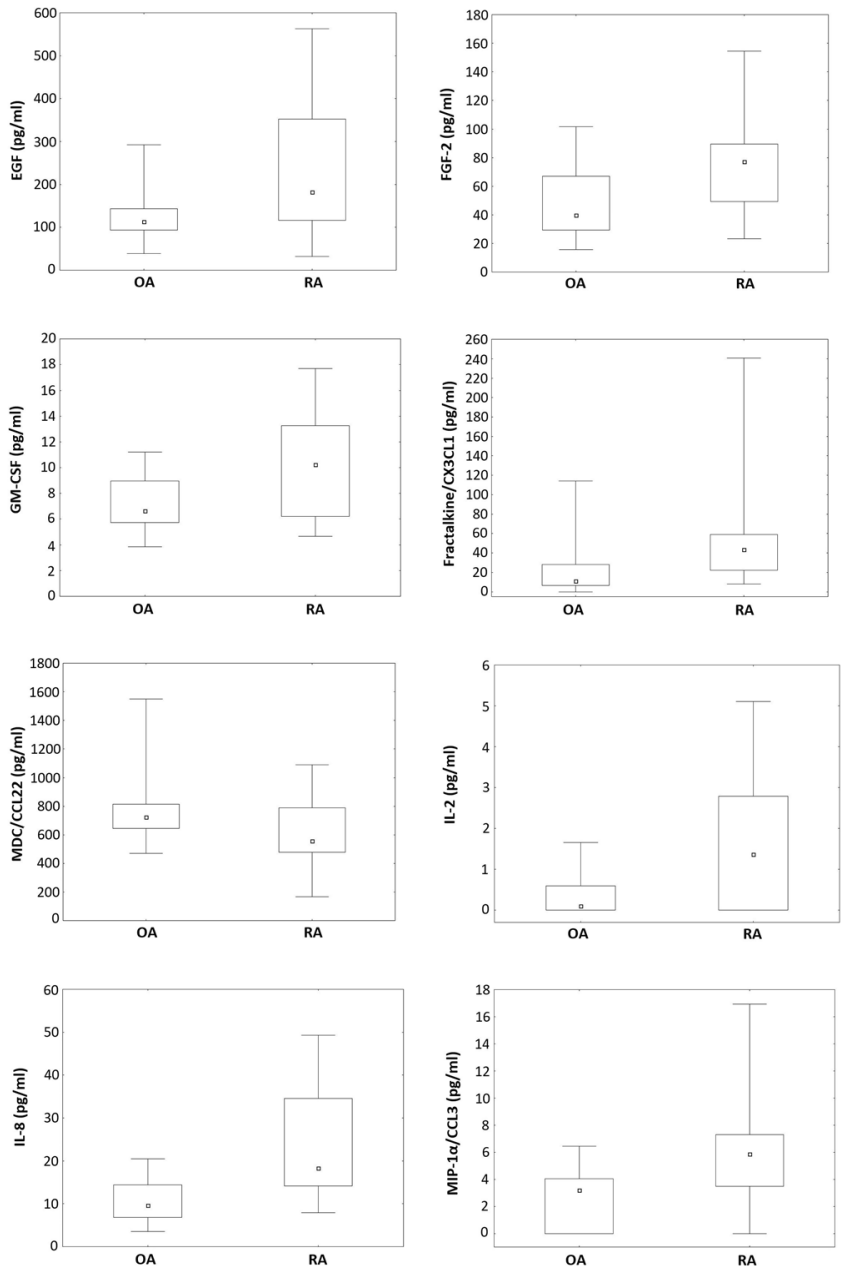

Fig. 1 Significantly different cytokine and chemokine serum levels in patients with established osteoarthritis and rheumatoid arthritis. Rheumatoid arthritis is associated with increased serum levels of: EGF $(p=0.031) \mathrm{FGF}-2(p=0.017)$, eotaxin/CCL11 $(p=0.037)$, G-CSF $\quad(p=0.014) \quad$ GM-CSF $(p=0.037), \quad$ fractalkine/CX3CL1 $(p=0.002), \quad$ IFN- $\alpha 2 \quad(p=0.002), \quad$ GRO/CXCL1 $\quad(p=0.01), \quad$ IL-2
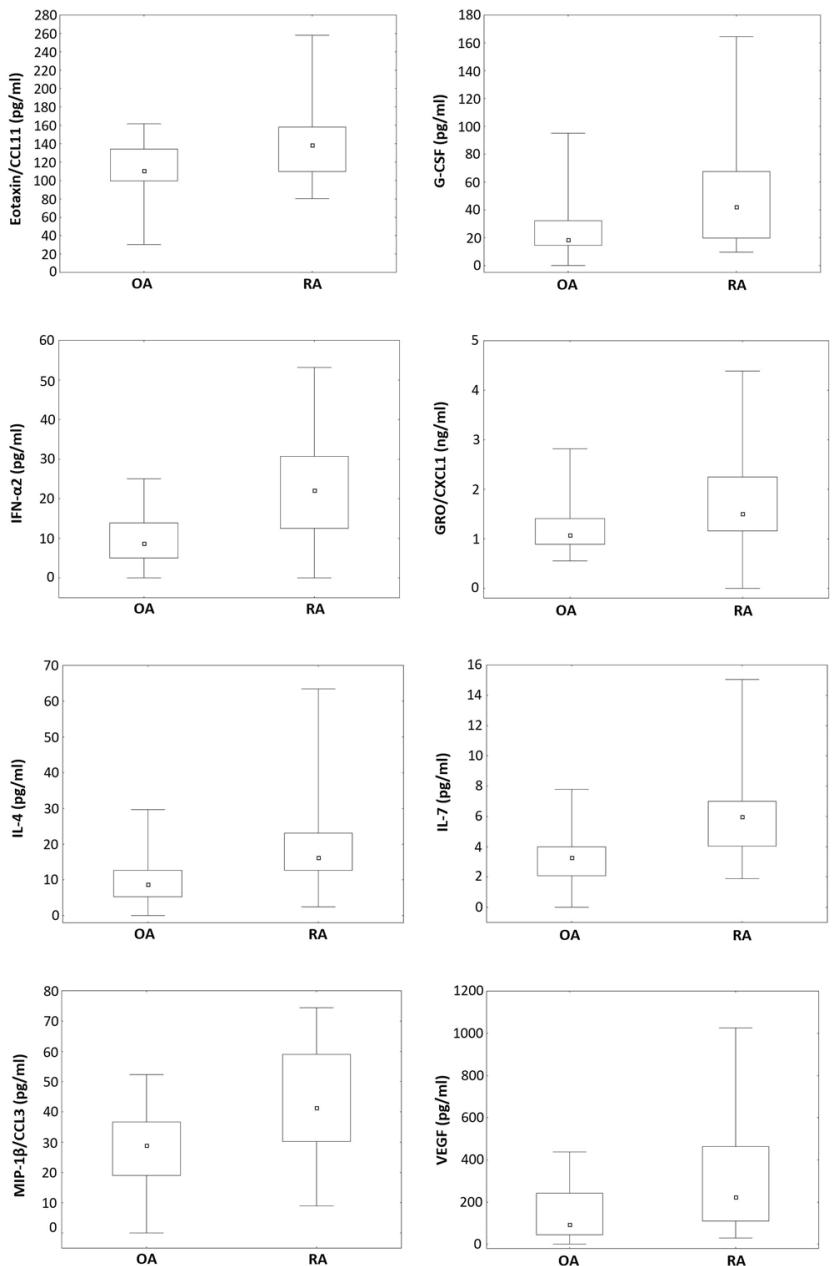

$(p=0.013)$, IL-4 $(p=0.017)$, IL-7 $\quad(p=0.003)$, IL-8 $\quad(p=0.0007)$, MIP-1- $\alpha / C C L 3(p=0.001)$, MIP-1 $\beta /$ CCL4 $(p=0.010)$ and VEGF $(p=0.027)$. MDC/CCL22 serum levels are lower in RA group $(p=0.034)$. Data are depictured as median with $25-75 \%$ percentiles and minimum - maximum and evaluated using the Mann-Whitney $\mathrm{U}$ test. Statistical significance was set at $p<0.05$ 
VEGF $(223.5,30.1-1025$ vs $92.9,0.0-437.8 ; p=0.027)$. Simultaneously, MDC/CCL22 serum levels were lower in RA group (556.2, 167.7-1090.7 vs 724.2, 470.5-1549.0; $p=0.034)$ (Fig. 1).

\section{Cytokines and chemokines' synovial fluid levels}

Within cytokines and chemokines detected in synovial fluid samples, FGF-2 $(p=0.84)$, Flt-3L $(p=0.08)$, MDC/CCL22 $(p=0.22)$, IL-15 $(p=0.52)$, IL-8 $(p=0.26)$, IP-10/CXCL10 $(p=0.16)$, MCP-1/CCL2 $(p=0.16)$ and MIP-1 $\beta / C C L 4$ $(p=0.75)$ and TNF $\alpha(p=0.12)$ have not differed between groups (Table 3 ).

Eotaxin/CCL11 $(25.5,10.4-62.2$ vs $12.5,3.8-56.4$; $p=0.001)$, GM-CSF $(10.4,3.1-25.1$ vs $6.9,0.0-26.1$; $p=0.01), \mathrm{GRO} / \mathrm{CXCL} 1$ (69.7; 0.0-895.6 vs 9.7, 0.0-249.0; $p=0.041)$, IL-10 (7.7, $0.0-41.3$ vs $0.0,0.0-5.2 ; p=0.003)$, sCD40L (24.2, 0.0-226.5 vs 5.5, 0.0-229.2; $p=0.001)$, IL1RA $(23.5,0.0-93.5$ vs $0.0,0.0-36.6 ; p=0.0005)$, IL- $1 \alpha$ $(8.6,0.0-55.9$ vs $0.0,0.0-31.2 ; p=0.003)$ and $\operatorname{VEGF}(382.5$, $0.0-1078.0$ vs $200.8,63.1-461.5 ; p=0.01)$ levels have been increased in RA individuals (Fig. 2).

\section{Discussion}

In our study, we have observed numerous alterations of cytokines and chemokines' secretion between low disease activity RA and OA subjects with few of them attracting greater attention.

Table 3 Comparable cytokine and chemokine synovial fluid levels in patients with established osteoarthritis and rheumatoid arthritis

\begin{tabular}{|c|c|c|c|c|c|c|c|}
\hline \multirow[t]{2}{*}{ Factor } & \multicolumn{3}{|l|}{ OA } & \multicolumn{3}{|l|}{ RA } & \multirow[b]{2}{*}{$p$} \\
\hline & Median & Min-max & $95 \% \mathrm{CI}$ & Median & Min-max & $95 \% \mathrm{CI}$ & \\
\hline FGF-2 (pg/ml) & 128.6 & $0.0-712.7$ & $180-324.8$ & 107.5 & $0.0-1357.0$ & $279.1-620.2$ & 0.84 \\
\hline Flt-3L (pg/ml) & 71.7 & $0.0-170.4$ & $36.9-66.7$ & 45.4 & $0.0-130.7$ & $28.8-66.2$ & 0.08 \\
\hline MDC/CCL22 (pg/ml) & 160.7 & $72.4-252.4$ & $36.7-66.2$ & 137.5 & $68.6-259.8$ & $45.3-100.6$ & 0.22 \\
\hline IL-15 (pg/ml) & 17.1 & $4.7-34.4$ & $5.3-9.6$ & 16.2 & $3.6-27.7$ & $5.7-13.1$ & 0.52 \\
\hline IL-8 (pg/ml) & 17.6 & $5.6-375.0$ & $72.0-129.9$ & 41.8 & $5.2-188.6$ & $36.1-80.2$ & 0.26 \\
\hline IP-10/CXCL10 (pg/ml) & 530.5 & 118.9- 1897.0 & $284.5-513.4$ & 654.8 & $472.3-1003.5$ & $146.4-325.3$ & 0.16 \\
\hline MCP-1/CCL2 (pg/ml) & 619.5 & $381.5-1351.0$ & $175.1-325.2$ & 1046.6 & $172.5-1576.0$ & $386.3-858.4$ & 0.16 \\
\hline MIP-1 $\beta /$ CCL4 (pg/ml) & 19.0 & $0.0-48.2$ & $8.9-16.1$ & 20.6 & $0.0-189.4$ & $35.5-79.0$ & 0.75 \\
\hline $\mathrm{TNF} \alpha(\mathrm{pg} / \mathrm{ml})$ & 6.15 & $0.0-11.7$ & $2.0-3.6$ & 8.8 & $0.0-31.3$ & $6.5-14.4$ & 0.12 \\
\hline
\end{tabular}

Statistical evaluation of differences was performed using the Mann-Whitney U test; $p$ indicates significance between analysed groups
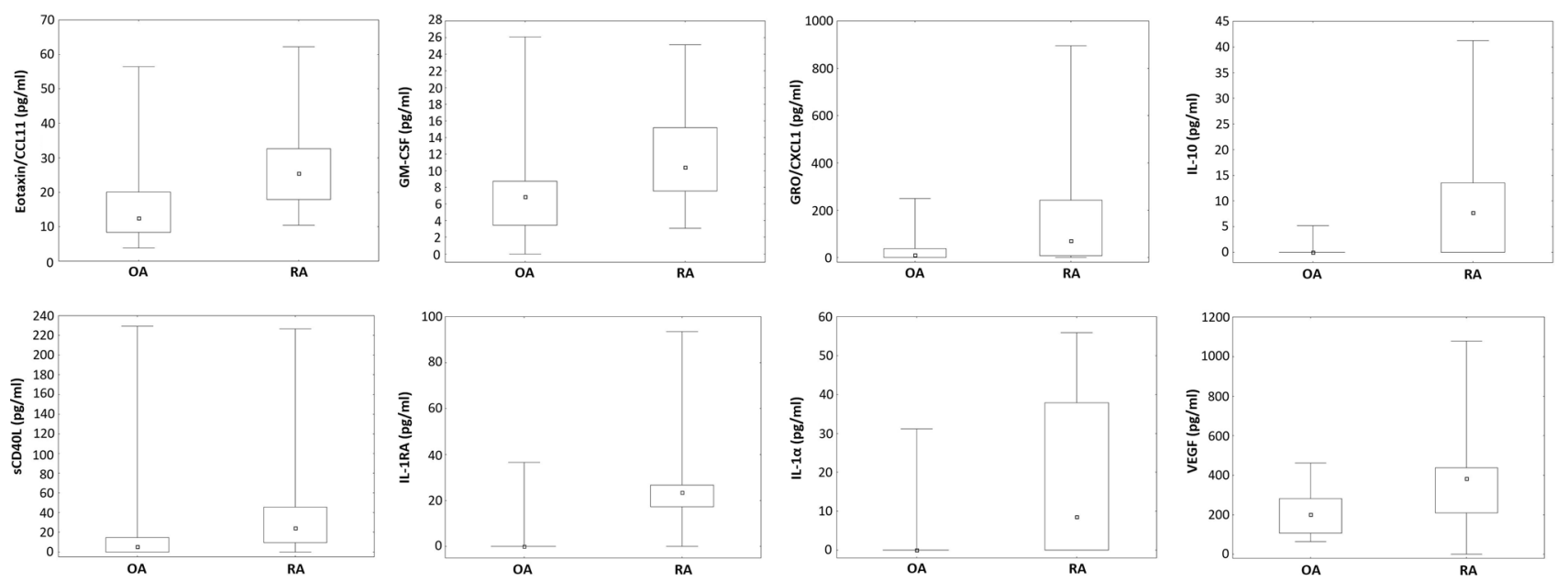

Fig. 2 Significantly different cytokine and chemokine synovial fluid levels in patients with established osteoarthritis and rheumatoid arthritis. Rheumatoid arthritis is associated with increased synovial fluid concentrations of: eotaxin/CCL11 $(p=0.001)$, GM-CSF $(p=0.01)$, GRO/CXCL1 $(p=0.041)$, IL-10 $(p=0.003)$, sCD40L

$(p=0.001)$, IL-1RA $(p=0.0005), \quad$ IL-1 $\alpha \quad(p=0.003)$ and VEGF $(p=0.01)$. Data are depictured as median with $25-75 \%$ percentiles and minimum-maximum and evaluated using the Mann-Whitney $U$ test. Statistical significance was set at $p<0.05$ 
IL-2 is a Th-1 cytokine required for: activation, proliferation, differentiation and survival of lymphocytes with special regard to regulatory $\mathrm{T}$ cells (Tregs). It is also necessary for Tregs stability in peripheral tissues. The protein is mainly produced by activated helper $\mathrm{T}$ cells, but the ability to secrete it is also shared by activated cytotoxic T cells, natural killer cells or dendritic cells. Disturbed IL-2 pathway has been described in various autoimmune disorders [13], e.g., RA sufferers display heightened titer of anti-IL-2 antibodies that may affect cytokine bioavailability for Tregs [14]. Our results indicate increased IL-2 concentration in serum samples and more frequent protein detection in synovial fluid samples (data not shown) isolated from RA subjects with low disease activity when compared to OA group. Increased cytokine plasma/serum levels have been described before RA symptoms manifestation, during disease onset [15] as well as in already established disease [16]. Raza et al. detected high IL-2 concentrations in synovial fluids of newly diagnosed patients, but those levels significantly dropped as RA progressed [17]. Our study confirmed high levels of IL-2 as characteristic for sufferers with established RA even with DAS28 score $\leq 3.2$.

$\mathrm{C}-\mathrm{C}$ motif ligand 11 chemokine (CCL11), also described as eotaxin, is a ligand for $\mathrm{C}-\mathrm{C}$ chemokine receptor 3 (CCR3) with the capacity to bind to other receptors as well [18]. CCL11 is secreted by: endothelial and epithelial cells, eosinophils, fibroblasts, keratinocytes, smooth muscle cells or chondrocytes [19], and its expression is induced by TNF and IL-4 [20]. It affects migration and activation of various leukocytes including: mast cells, eosinophils, Th2 lymphocytes, basophils, neutrophils and macrophages $[18,19,21]$. CCL11 and CCR3 production was proven in synovial tissue and synoviocytes of RA-affected joints, with the expression being stimulated by TNF and CCL11 itself. It was also confirmed that chemokine promotes synoviocytes migration during RA [18]. CCL11/CCR3 axis is also believed to affect bone destruction [19]. Surprisingly, Syversen et al. distinguished increased serum CCL11 levels as a predictor of slower radiographic progression of early RA [22]. We have found elevated chemokine concentration in serum and synovial fluid of our RA group when compared to OA counterparts, which further indicates involvement of this protein in RA-induced joint inflammation. We have observed significant correlation between synovial fluid concentrations of CCL11 and TNF $\alpha$, but not IL-4 (data not shown). Similar results have been published by Wakabayashi et al. when comparing protein serum levels between newly diagnosed RA sufferers and healthy controls as well as synovial fluid concentrations between RA group and OA subjects. Authors also revealed correlation between synovial fluid quantities of CCL11 and TNF and concluded chemokines' responsibility for destructive activity of synoviocytes [18]. Increased plasma CCL11 concentration in newly diagnosed
RA patients was also described by Kokkonen et al. Group even indicated it as one of the most important factors that shows altered expression due to RA onset [15]. Analyses conducted on long-standing RA patients have also shown increase in CCL11 serum concentration when compared to healthy volunteers along with its correlation with TNF levels. However, in referred study, chemokine concentrations were highest in synovial fluid samples [21], which is not convergent with our observations.

$\mathrm{C}-\mathrm{X}-\mathrm{C}$ motif chemokine ligand 1 (CXCL1)/GRO is a chemotactic cytokine engaged in the development of many inflammatory disorders, although its significance has been most extensively evaluated in tumors. CXCL1 serves as potent regulator of: neutrophil recruitment, angiogenesis and wound healing [23, 24]. Its receptors include, inter alia, CXCR2 (CXC motifs receptors 2) that is mainly expressed on neutrophils, but can be also detected on: monocytes, NK cells, mast cells, basophils, cytotoxic T and endothelium. In the course of RA, synovial macrophages, recognized as main source of chemokine, induce CXCL1-dependent neutrophil migration into the joint, where cells become activated and produce further factors to amplify their own recruitment and stimulation [25]. CXCL1 could also be responsible for hypertrophy and apoptosis of chondrocytes [26]. Sadik et al., utilizing murine model, indicated direct IL-17-induced secretion of CXCL1 by synovial fibroblasts during effector phase of arthritis [27]. Our results signify increased concentrations of chemokine in blood sera as well as synovial fluids of low disease activity RA patients when compared to OA counterparts. Similar results have been published by Koch et al. with authors indicating RA synovial tissue-isolated neutrophils as additional source of chemokine [28]. Flow cytometry and RT-PCR analyses revealed enhanced CXCL1 expression in chondrocytes isolated from cartilages of RA and OA patients when compared to healthy subjects [29]. Increased CXCL1 mRNA expression and protein production in synovial fibroblasts isolated from RA and OA sufferers when contrasted with healthy donors cells have also been described [24]. CXCL1 concentrations in RA and OA bone marrow plasma have been found similar [30].

Another chemokine that brought our attention was $\mathrm{C}-\mathrm{C}$ motif ligand 22 chemokine (CCL22) also known as macrophage-derived chemokine (MDC) - protein produced by macrophages, dendritic cells or osteoclasts. It selectively binds to the $\mathrm{C}-\mathrm{C}$ chemokine receptor 4 (CCR4) that is expressed by Th2, Th17 and Tregs cells [31]. CCL22 is further described as attenuating the development and function of Tregs by inhibiting the expression of Foxp3 transcription factor in STAT5-dependent manner [32]. Its role in inflammation could be considered quite ambiguous, since this potent chemotactic molecule affects both anti- and pro-inflammatory leukocytes [33]. It was also implied that CCL22, through pro-apoptotic activity on chondrocytes, 
takes direct part in initiating cartilage degeneration in OAchemokine was appointed biomarker of cartilage degeneration in OA [34] and potential biomarker of early OA [35]. Surprisingly, CCL22 serum levels were lowered in our RA patients when compared to OA volunteers, but the differences in protein concentrations in synovial fluid samples did not reach statistical significance. Numerous publications reported increase in CCL22 sera levels of RA sufferers when contrasted with healthy [31, 32] or OA [31] individuals. Similar results were published concerning synovial fluid samples [31, 36]. Immunohistochemical analyses also revealed different distribution of CCL22 + cells in synovial tissue of RA and OA subjects [31]. Rump et al. did not find differences in chemokine concentration between RA and OA groups when analysing serum and synovial fluid samples, but reported more common expression of CCL22 in endothelial cells of synovium vessels in RA patients when compared to non-RA individuals. Authors concluded that this increased chemokine production may be responsible for augmented leukocytes recruitment to RA synovium [37]. Our results could be considered contradictory to those studies, since they suggest greater systemic production of CCL22 in OA patients and comparable protein levels in joint tissue. Although we are unable to pinpoint cause of differences between ours and others results, we would like to emphasize more frequent hypertension occurrence in OA group. To the best of our knowledge, there are no publications concerning CCL22 levels in hypertensive patients, but murine model analyses performed by Zhong et al. suggest increased chemokine secretion due to disease development [38]. Ren et al. described increased protein expression in articular chondrocytes during OA-induced cartilage damage [34]. The following studies of this group also revealed: heightened synovial fluid chemokine concentration in OA group when compared to healthy subjects, its correlation with synovitis and constricting impact of CCL22 on antiinflammatory cytokines expression (33).

We also observed elevated concentration of bone-marrow-derived factors including granulocyte-macrophage colony-stimulating factor (GM-CSF). Numerous cells have been described as GM-CSF producers: fibroblasts, synoviocytes, innate lymphoid cells, endothelial cells and activated T lymphocytes. Its secretion is stimulated by IL-17 and IL-2. GM-CSF is indicated as a main cytokine responsible for maintaining RA-induced joint inflammation. Synoviocytes, lymphocytes and innate lymphoid cells initiate inflammatory cascade in GM-CSF-dependent manner that leads to monocyte/macrophage activation and severe release of: IL-1, IL-6 and TNF. These cytokines, among other things, are responsible for bone destruction [39]. In our study, both serum and synovial fluid concentrations of GM-CSF were heightened in low disease activity RA sufferers when compared to OA subjects. Similar results were described numerous times including patients suffering from moderate to severe forms of the disease $[40,41]$. On the other hand, Raza et al. described elevated quantities of synovial fluid GM-CSF only in early diagnosed patients [17]. Continuously heightened GM-CSF serum and synovial fluid levels that have been observed by our group support the concept of protein being promising therapeutic target in RA as indicated by others [41].

We also noticed heightened levels of angiogenesis related factors including vascular endothelial growth factor (VEGF). VEGF is a pro-angiogenic protein-it promotes new blood vessels formation by, inter alia, stimulating proliferation and migration of endothelial cells. VEGF production is induced by hypoxic conditions and some cytokines. Growth factor also promotes inflammation maintenance in various conditions including RA. VEGF is considered responsible for synovial hypertrophy, swelling or cartilage and bone degeneration in RA [42]. We have detected increased growth factor concentration in serum as well as synovial fluid samples of RA patients when contrasted with OA volunteers. Kokkonen et al. reported raised growth factor serum levels in newly diagnosed patient. Group even indicated this protein crucial factor that discriminates between individuals before disease onset and patients with already established RA [15]. Results similar to ours were presented by Raza et al. when describing VEGF synovial fluid levels-highest concentration was characteristic for newly diagnosed individuals, but significant differences were also recognized between longstanding patients and OA controls [17]. Studies showed not only increased concentration of VEGF in serum and synovial fluid in RA patients [43], but also its correlation with inflammation and joint destruction markers [44]. Alterations of VEGF serum concentrations have been demonstrated a valuable response to treatment indicator [45], which is consistent with the fact that our RA patients, despite the treatment, failed to reach remission.

IL-10 is well-characterized immunomodulatory cytokine that affects innate and adaptive immune responses. It inhibits, inter alia, nuclear factor kappa B (NF- $\mathrm{kB})$ pathway - this leads to suppression of various pro-inflammatory cytokines, including the ones strongly associated with arthritis [46, 47]. IL-10 affects production of: IL-2, IL-5, IFN- $\gamma$, TNF $\alpha$ or GM-CSF by CD4 + T cells. Cytokine is also recognized for decreasing MHC class II complex expression (48). IL-10 is produced by activated lymphocytes, monocytes and macrophages [48, 49], and its production by $\mathrm{T}$ helper cells is described as critical self-regulation mechanism [48]. IL-10 has been detected in synovial membrane and fluids of RA individuals - it is possible that cytokine is powerful enough to control acute inflammation, but becomes inadequate in case of constant stimulation that accompanies arthritis [49]. Anti-inflammatory properties of IL-10 have been well documented, but generic effect of its activity is 
context-dependent-e.g., simultaneous IL-2 and IL-10 stimulation increases the cytotoxicity of CD8 + T lymphocytes [48]. IL-10 also promotes: proliferation, survival and immunoglobulin production by B lymphocytes [47]. We have detected higher IL-10 concentrations in synovial fluid samples of low disease activity RA patients when contrasted with OA volunteers - in the latter case, protein was hardly ever detected. Cytokine was also undetectable in blood samples. Lettesjö et al. have also detected higher concentrations of IL-10 in synovial fluids of RA patients when compared to individuals with other arthritic lesions with protein often failing to reach detection limit in the second group [50]. Hernández-Bello et al., investigating role of genetic factors on IL-10 expression in moderate disease activity RA, observed heightened expression of cytokine mRNA in patients' leukocytes when compared to cells isolated from healthy subjects, but did not detect significant differences when analysing serum protein levels $(p=0.2)$ [51]. On the other hand, Tukaj et al. detected increased IL-10 serum levels in moderate disease activity RA patients [52]. Elevated cytokine levels were also found in sera and synovial fluids of RA patients by Cush et al. [53]. Saxena et al. suggested that increased IL-10 secretion in RA individuals could simultaneously suppress cytokines' production and cellular responses as well as intensify humoral autoimmune reactions (47).

IL-1RA is a natural endogenous IL-1 receptor type 1 (IL1R1) antagonist, and therefore, it is considered antagonist of both-IL- $1 \alpha$ and IL- $1 \beta$ signaling. Interestingly, binding affinity of IL-1RA and cytokines to the receptor is similar, enabling efficient suppression IL-1R1-mediated signaling by the antagonist. IL-1RA is described as essential in tissue repair and regeneration in IL- $1 \alpha$ - and IL- $1 \beta$-based pathologies. Since cartilage destruction in RA is primarily caused by IL- $1 \beta$, the importance of IL-1RA in synovial inflammation suppression could be deemed invaluable [54, 55]. Numerous studies have proved attenuation of disease symptoms due to antagonist administration [56]. Moreover, mice with IL-1RA knockout develop RA-like disease and are utilized as RA model [57]. IL-1RA serum levels in our RA patients were higher when contrasted with OA sufferers, but observed differences did not reach statistical significance. However, our low disease activity RA group was characterized by higher IL-1RA as well as IL-1 $\alpha$ concentrations in synovial fluid samples, with proteins being rarely detected in OA volunteers. Observed differences could be, at least partially, explained by therapeutic interventions-majority of our RA patients have been treated with DMARDs and/ or steroids with such therapies being described as promoting IL-1RA secretion [58]. Increased cytokine secretion could also result from more pronounced joint destruction in our RA subject when compared to OA group and/or fairly unavoidable disease progression-significantly higher
IL-1RA levels have been observed in destructive RA arthritis patients when contrasted with non-destructive arthritis [59]. Observed alterations in IL-1RA synovial fluid levels could also constitute response to heightened IL- $1 \alpha$ concentrations - we have observed moderate $(R=0.45)$ correlation between both cytokines in group consisting of RA and OA patients (data not shown).

\section{Limitations of the study}

The greatest limitation of our study is low number of participants. Individuals suffering from RA were significantly younger and had lower BMI scores, although it has been reported that RA patients undergo knee arthroplasty younger than their OA counterparts [60]. All of our RA patients have already received standard treatment which may have had significant impact on our results. OA volunteers more frequently suffered from arterial hypertension. Our conclusions are rather of a speculative nature and will require further analyses conducted on larger population as well as patients in different stages of RA progression.

\section{Conclusion}

Development of the RA is a complex process that involves interactions between immune cells and numerous cytokines/ chemokines. These factors, by affecting subsequent cell populations, are responsible for local and systemic symptoms of RA. We have observed alterations in blood serum and synovial fluid concentrations of many cytokines and chemokines, out of which: IL-2, eotaxin/CCL11, MDC/CCL22, GMCSF, VEGF, IL-10 and IL-1RA have caught our attention. The unexpected decrease of MDC/CCL22 serum concentration in RA patients is particularly interesting and could be considered target of more thorough investigation. Our results considering anti-inflammatory cytokines may indicate continuous attempt to restore local cytokine homeostasis in low disease activity RA patients. However, increased concentrations of numerous pro-inflammatory factors as well as inability to achieve remission suggest insufficiency of those mechanisms even in a case of good RA management. Distinguished factors could serve as possible indicators of disease progression even in low disease activity RA patients.

Author contributions Conceptualization: Maria Skrzypkowska, Mariusz Stasiak, PT, and PŁ; study design: PT and PŁ; sample collection: Mariusz Stasiak and JC; data acquisition: JS, JC, and AM; data analyses and interpretation: Maria Skrzypkowska, Mariusz Stasiak, and BS; statistical analyses: Maria Skrzypkowska and AB; funding acquisition: PT; original draft preparation: Maria Skrzypkowska; manuscript review and editing: Maria Skrzypkowska, Mariusz Stasiak, and BS; 
supervision: PT and PŁ; All authors contributed to the study conception and design as well as read and approved the final version of the manuscript. Authors take full responsibility for all aspects of the presented work.

Funding This work was supported by The State Committee for Scientific Research ST49 of Medical University of Gdańsk [awarded to Prof. Piotr Trzonkowski].

Data availability Data underlying this article will be shared on reasonable request to the corresponding author.

\section{Declarations}

Conflict of interest All authors declare that they have no conflict of interest.

Ethics approval The study was approved by the Ethics Committee of Medical University of Gdańsk (consent no NKBBN/642/2018 received on December 10, 2018) and our investigation was carried out in accordance with the Code of 8 Ethics of the World Medical Association (Declaration of Helsinki) for experiments on human subjects. Written informed consent was obtained from all participants.

Open Access This article is licensed under a Creative Commons Attribution 4.0 International License, which permits use, sharing, adaptation, distribution and reproduction in any medium or format, as long as you give appropriate credit to the original author(s) and the source, provide a link to the Creative Commons licence, and indicate if changes were made. The images or other third party material in this article are included in the article's Creative Commons licence, unless indicated otherwise in a credit line to the material. If material is not included in the article's Creative Commons licence and your intended use is not permitted by statutory regulation or exceeds the permitted use, you will need to obtain permission directly from the copyright holder. To view a copy of this licence, visit http://creativecommons.org/licenses/by/4.0/.

\section{References}

1. Chen Z, Bozec A, Ramming A, Schett G (2019) Anti-inflammatory and immune-regulatory cytokines in rheumatoid arthritis. Nat Rev Rheumatol 15:9-17. https://doi.org/10.1038/ s41584-018-0109-2

2. Haringman JJ, Gerlag DM, Zwinderman AH, Smeets TJM, Kraan MC, Baeten D, McInnes IB, Bresnihan B, Tak PP (2005) Synovial tissue macrophages: a sensitive biomarker for response to treatment in patients with rheumatoid arthritis. Ann Rheum Dis 64:834-838. https://doi.org/10.1136/ard.2004.029751

3. Koo J, Kim S, Jung WJ, Lee YE, Song GG, Kim KS, Kim MY (2013) Increased lymphocyte infiltration in rheumatoid arthritis is correlated with an increase in LTi-like cells in Synovial fluid. Immune Netw 13:240-248. https://doi.org/10.4110/in.2013.13.6. 240

4. Zhang C (2021) Flare-up of cytokines in rheumatoid arthritis and their role in triggering depression: shared common function and their possible applications in treatment. Biomed Rep 14:16. https://doi.org/10.3892/br.2020.1392

5. McInnes I, Buckley C, Isaacs J (2016) Cytokines in rheumatoid arthritis_-shaping the immunological landscape. Nat Rev Rheumatol 12:63-68. https://doi.org/10.1038/nrrheum.2015.171
6. Orozco L, Munar A, Soler R, Alberca M, Soler F, Huguet M, Sentís J, Sánchez A, García-Sancho J (2013) Treatment of knee osteoarthritis with autologous mesenchymal stem cells: a pilot study. Transplantation 95:1535-1541. https://doi.org/10.1097/tp. 0b013e318291a2da

7. Maumus M, Manferdini C, Toupet K, Chuchana P, Casteilla L, Gachet M, Jorgensen C, Lisignoli G, Noël D (2017) Thrombospondin-1 partly mediates the cartilage protective effect of adiposederived mesenchymal stem cells in osteoarthritis. Front Immunol 8:1638. https://doi.org/10.3389/fimmu.2017.01638

8. Miller R, Miller R, Malfait AM (2014) Osteoarthritis joint pain: the cytokine connection. Cytokine 70:185-193. https://doi.org/ 10.1016/j.cyto.2014.06.019

9. Ponchel F, Burska AN, Hensor EM, Raja R, Campbell M, Emery P, Conaghan PG (2015) Changes in peripheral blood immune cell composition in osteoarthritis. Osteoarthritis Cartilage 23:1870-1878. https://doi.org/10.1016/j.joca.2015.06.018

10. Bahlas S, Damiati L, Dandachi N, Sait H, Alsefri M, Pushparaj PN (2019) Rapid immunoprofiling of cytokines, chemokines and growth factors in patients with active rheumatoid arthritis using Luminex Multiple Analyte Profiling technology for precision medicine. Clin Exp Rheumatol 37:112-119

11. Aletaha D, Neogi T, Silman AJ, Funovits J, Felson DT, Bingham CO, Birnbaum NS, Burmester GR, Bykerk VP, Cohen MD, Combe B, Costenbader KH, Dougados M, Emery P, Ferraccioli G, Hazes JWM, Hobbs K, Huizinga TWJ, Kavanaugh A, Kay J, Kvien TK, Laing T, Mease P, Ménard HA, Moreland LW, Naden RL, Pincus T, Smolen JS, Stanislawska-Biernat E, Symmons D, Tak PP, Upchurch KS, Vencovský J, Wolfe F, Hawker G (2010) Rheumatoid arthritis classification criteria: an American College of Rheumatology/European League Against Rheumatism collaborative initiative. Arthritis Rheum 62:2569-2581. https:// doi.org/10.1002/art.27584

12. Kolasinski SL, Neogi T, Hochberg MC, Oatis C, Guyatt G, Block J, Callahan L, Copenhaver C, Dodge C, Felson D, Gellar K, Harvey WF, Hawker G, Herzig E, Kwoh CK, Nelson AE, Samuels J, Scanzello C, White D, Wise B, Altman RD, DiRenzo D, Fontanarosa J, Giradi G, Ishimori M, Misra D, Shah AA, Shmagel AK, Thoma LM, Turgunbaev M, Turner AS, Reston J (2020) 2019 American College of Rheumatology/arthritis foundation guideline for the management of osteoarthritis of the hand, hip, and knee. Arthritis Rheumatol 72:220-233. https:// doi.org/10.1002/art.41142

13. Klatzmann D, Abbas AK (2015) The promise of low-dose interleukin-2 therapy for autoimmune and inflammatory diseases. Nat Rev Immunol 15:283-294. https://doi.org/10.1038/nri3823

14. Bo M, Niegowska M, Erre GL, Piras M, Longu MG, Manchia P, Manca M, Passiu G, Sechi LA (2018) Rheumatoid arthritis patient antibodies highly recognize IL-2 in the immune response pathway involving IRF5 and EBV antigens. Sci Rep 8:1789. https://doi.org/10.1038/s41598-018-19957-z

15. Kokkonen H, Söderström I, Rocklöv J, Hallmans G, Lejon K, Rantapää Dahlqvist S (2010) Up-regulation of cytokines and chemokines predates the onset of rheumatoid arthritis. Arthritis Rheum 62:383-391. https://doi.org/10.1002/art.27186

16. Oncül O, Top C, Ozkan S, Cavuşlu S, Danaci M (2002) Serum interleukin 2 levels in patients with rheumatoid arthritis and correlation with insulin sensitivity. J Int Med Res 30:386-390. https://doi.org/10.1177/147323000203000404

17. Raza K, Falciani F, Curnow J, Ross E, Lee CY, Akbar AN, Lord JM, Gordon C, Buckley CD, Salmon M (2005) Early rheumatoid arthritis is characterized by a distinct and transient synovial fluid cytokine profile of T cell and stromal cell origin. Arthritis Res Ther 7:784-795. https://doi.org/10.1186/ar1733

18. Wakabayashi K, Isozaki T, Tsubokura Y, Fukuse S, Kasama $\mathrm{T}$ (2021) Eotaxin-1/CCL11 is involved in cell migration in 
rheumatoid arthritis. Sci Rep 11:7937. https://doi.org/10.1038/ s41598-021-87199-7

19. Kindstedt E, Koskinen Holm C, Sulniute R, Martinez-Carrasco I, Lundmark R, Lundberg P (2017) CCL11, a novel mediator of inflammatory bone resorption. Sci Rep 7:5334. https://doi.org/ 10.1038/s41598-017-05654-w

20. Miyamasu M, Nakajima T, Misaki Y, Izumi S, Tsuno N, Kasahara T, Yamamoto K, Morita Y, Hirai K (1999) Dermal fibroblasts represent a potent major source of human eotaxin: In vitro production and cytokine-mediated regulation. Cytokine 11:751-758. https://doi.org/10.1006/cyto.1999.0487

21. Liu X, Zhang H, Chang X, Shen J, Zheng W, Xu Y, Wang J, Gao $\mathrm{W}, \mathrm{He} S$ (2017) Upregulated expression of CCR3 in rheumatoid arthritis and CCR3-dependent activation of fibroblast-like synoviocytes. Cell Biol Toxicol 33:15-26. https://doi.org/10.1007/ s10565-016-9356-7

22. Syversen SW, Goll GL, Haavardsholm EA, Bøyesen P, Lea T, Kvien TK (2008) A high serum level of eotaxin (CCL 11) is associated with less radiographic progression in early rheumatoid arthritis patients. Arthritis Res Ther 10:28. https://doi.org/ 10.1186/ar2381

23. Korbecki J, Barczak K, Gutowska I, Chlubek D, BaranowskaBosiacka I (2022) CXCL1: gene, promoter, regulation of expression, mRNA stability, regulation of activity in the intercellular space. Int J Mol Sci 23:792. https://doi.org/10.3390/ijms230207 92

24. Hou SM, Chen PC, Lin CM, Fang ML, Chi MC, Liu JF (2020) CXCL1 contributes to IL-6 expression in osteoarthritis and rheumatoid arthritis synovial fibroblasts by CXCR2, c-Raf, MAPK, and AP-1 pathway. Arthritis Res Ther 22:251. https://doi.org/10. 1186/s13075-020-02331-8

25. Miyabe Y, Miyabe C, Iwai Y, Luster AD (2020) Targeting the chemokine system in rheumatoid arthritis and vasculitis. JMA J 3:182-192. https://doi.org/10.31662/jmaj.2020-0019

26. Olivotto E, Vitellozzi R, Fernandez P, Falcieri E, Battistelli M, Burattini S, Facchini A, Flamigni F, Santi S, Facchini A, Borzi' RM (2007) Chondrocyte hypertrophy and apoptosis induced by GROalpha require three-dimensional interaction with the extracellular matrix and a co-receptor role of chondroitin sulfate and are associated with the mitochondrial splicing variant of cathepsin B. J Cell Physiol 210:417-427. https://doi.org/10.1002/jcp.20864

27. Sadik CD, Kim ND, Alekseeva E, Luster AD (2011) IL-17RA signaling amplifies antibody-induced arthritis. PLoS One 6:e26342. https://doi.org/10.1371/journal.pone.0026342

28. Koch AE, Kunkel SL, Shah MR, Hosaka S, Halloran MM, Haines GK, Burdick MD, Pope RM, Strieter RM (1995) Growth-related gene product alpha. A chemotactic cytokine for neutrophils in rheumatoid arthritis. J Immunol 155:3660-3666

29. Borzi RM, Mazzetti I, Macor S, Silvestri T, Bassi A, Cattini L, Facchini A (1999) Flow cytometric analysis of intracellular chemokines in chondrocytes in vivo: constitutive expression and enhancement in osteoarthritis and rheumatoid arthritis. FEBS Lett 455:238-242. https://doi.org/10.1016/s0014-5793(99)00886-8

30. Kuca-Warnawin EH, Kurowska WJ, Radzikowska A, Massalska MA, Burakowski T, Kontny E, Słowińska I, Gasik R, Maśliński W (2016) Different expression of chemokines in rheumatoid arthritis and osteoarthritis bone marrow. Reumatologia 54:51-53. https:// doi.org/10.5114/reum.2016.60212

31. Flytlie H, Hvid M, Lindgreen E, Kofod-Olsen E, Petersen EL, Jørgensen A, Deleuran M, Vestergaard C, Deleuran B (2010) Expression of MDC/CCL22 and its receptor CCR4 in rheumatoid arthritis, psoriatic arthritis and osteoarthritis. Cytokine 49:24-29. https://doi.org/10.1016/j.cyto.2009.10.005

32. Wang L, Wang L, Hao P, Cao Q, Zhang Z (2020) Anti-CCL22 increases regulatory $\mathrm{T}$ cells in $\mathrm{CD} 4+\mathrm{T}$ cells of rheumatoid arthritis patients via STAT5 pathway. Exp Ther Med 19:21272132. https://doi.org/10.3892/etm.2019.8404

33. Ren G, Al-Jezani N, Railton P, Powell JN (2020) CCL22 induces pro-inflammatory changes in fibroblast-like synoviocytes. iScience 24:101943. https://doi.org/10.1016/j.isci.2020.101943

34. Ren G, Whittaker JL, Leonard C, De Rantere D, Pang DSJ, Salo P, Fritzler M, Kapoor M, de Koning APJ, Jaremko JL, Emery CA, Krawetz RJ (2019) CCL22 is a biomarker of cartilage injury and plays a functional role in chondrocyte apoptosis. Cytokine 115:32-44. https://doi.org/10.1016/j.cyto.2018.11.030

35. Heard BJ, Fritzler MJ, Wiley P, McAllister J, Martin L, ElGabalawy H, Hart DA, Frank CB, Krawetz R (2013) Intraarticular and systemic inflammatory profiles may identify patients with osteoarthritis. J Rheumatol 40:1379-1387. https://doi.org/10. 3899/jrheum. 121204

36. Altobelli E, Angeletti PM, Piccolo D, De Angelis R (2017) Synovial fluid and serum concentrations of inflammatory markers in rheumatoid arthritis, psoriatic arthritis and osteoarthitis: a systematic review. Curr Rheumatol Rev 13:170-179. https://doi.org/10. 2174/1573397113666170427125918

37. Rump L, Mattey DL, Kehoe O, Middleton J (2017) An initial investigation into endothelial CC chemokine expression in the human rheumatoid synovium. Cytokine 97:133-140. https://doi. org/10.1016/j.cyto.2017.05.023

38. Zhong Y, Tang R, Lu Y, Wang W, Xiao C, Meng T, Ao X, Li X, Peng L, Kwadwo Nuro-Gyina P, Zhou Q (2020) Irbesartan may relieve renal injury by suppressing Th22 cells chemotaxis and infiltration in Ang II-induced hypertension. Int Immunopharmacol 87:106789. https://doi.org/10.1016/j.intimp.2020.106789

39. Takeuchi Y, Hirota K, Sakaguchi S (2019) Synovial tissue inflammation mediated by autoimmune T cells. Front Immunol 10:1989. https://doi.org/10.3389/fimmu.2019.01989

40. Darrieutort-Laffite C, Boutet MA, Chatelais M, Brion R, Blanchard F, Heymann D, Le Goff B (2014) IL- $1 \beta$ and TNF $\alpha$ promote monocyte viability through the induction of GM-CSF expression by rheumatoid arthritis synovial fibroblasts. Mediators Inflamm 2014:241840. https://doi.org/10.1155/2014/241840

41. Lee K, Achuthan A, Hamilton J (2020) GM-CSF: a promising target in inflammation and autoimmunity. Immunotargets Ther 9:225-240. https://doi.org/10.2147/itt.s262566

42. Llorián-Salvador M, González-Rodríguez S (2018) Painful understanding of VEGF. Front Pharmacol 9:1267. https://doi.org/10. 3389/fphar.2018.01267

43. Paradowska-Gorycka A, Pawlik A, Romanowska-Prochnicka K, Haladyj E, Malinowski D, Stypinska B, Manczak M, Olesinska M (2016) Relationship between VEGF gene polymorphisms and serum VEGF protein levels in patients with rheumatoid arthritis. PLoS One 11(8):e0160769. https://doi.org/10.1371/journal.pone. 0160769

44. Clavel G, Bessis N, Lemeiter D, Fardellone P, Mejjad O, Ménard JF, Pouplin S, Boumier P, Vittecoq O, Le Loët X, Boissier MC (2007) Angiogenesis markers (VEGF, soluble receptor of VEGF and angiopoietin-1) in very early arthritis and their association with inflammation and joint destruction. Clin Immunol 124:158164. https://doi.org/10.1016/j.clim.2007.04.014

45. Kim JW, Kong JS, Lee S, Yoo SA (2020) Angiogenic cytokines can reflect the synovitis severity and treatment response to biologics in rheumatoid arthritis. Exp Mol Med 52:843-853. https://doi. org/10.1038/s12276-020-0443-8

46. Greenhill CJ, Jones GW, Nowell MA, Newton Z, Harvey AK, Moideen AN, Collins FL, Bloom AC, Coll RC, Robertson AA, Cooper MA, Rosas M, Taylor PR, O'Neill LA, Humphreys IR, Williams AS, Jones SA (2014) Interleukin-10 regulates the inflammasome-driven augmentation of inflammatory arthritis and joint destruction. Arthritis Res Ther 16:419. https://doi.org/ 10.1186/s13075-014-0419-y 
47. Saxena A, Khosraviani S, Noel S, Mohan D, Donner T, Hamad AR (2015) Interleukin-10 paradox: a potent immunoregulatory cytokine that has been difficult to harness for immunotherapy. Cytokine 74:27-34. https://doi.org/10.1016/j.cyto.2014.10.031

48. Mannino MH, Zhu Z, Xiao H, Bai Q, Wakefield MR, Fang Y (2015) The paradoxical role of IL-10 in immunity and cancer. Cancer Lett 367:103-107. https://doi.org/10.1016/j.canlet.2015. 07.009

49. Brzustewicz E, Bryl E (2015) The role of cytokines in the pathogenesis of rheumatoid arthritis-Practical and potential application of cytokines as biomarkers and targets of personalized therapy. Cytokine 76:527-536. https://doi.org/10.1016/j.cyto.2015.08.260

50. Lettesjö H, Nordström E, Ström H, Nilsson B, Glinghammar B, Dahlstedt L, Möller E (1998) Synovial fluid cytokines in patients with rheumatoid arthritis or other arthritic lesions. Scand J Immunol 48:286-292. https://doi.org/10.1046/j.1365-3083.1998. 00399.x

51. Hernández-Bello J, Oregón-Romero E, Vázquez-Villamar M, García-Arellano S, Valle Y, Padilla-Gutiérrez JR, Román-Fernández IV, Palafox-Sánchez CA, Martínez-Bonilla GE, Muñoz-Valle JF (2017) Aberrant expression of interleukin-10 in rheumatoid arthritis: relationship with IL10 haplotypes and autoantibodies. Cytokine 95:88-96. https://doi.org/10.1016/j.cyto.2017.02.022

52. Tukaj S, Kotlarz A, Jóźwik A, Smoleńska Z, Bryl E, Witkowski JM, Lipińska B (2010) Cytokines of the Th1 and Th2 type in sera of rheumatoid arthritis patients; correlations with anti-Hsp40 immune response and diagnostic markers. Acta Biochim Pol $57: 327-332$

53. Cush JJ, Splawski JB, Thomas R, McFarlin JE, Schulze-Koops H, Davis LS, Fujita K, Lipsky PE (1995) Elevated interleukin-10 levels in patients with rheumatoid arthritis. Arthritis Rheum 38:96-104. https://doi.org/10.1002/art.1780380115

54. Harrell CR, Markovic BS, Fellabaum C, Arsenijevic N, Djonov V, Volarevic V (2020) The role of Interleukin 1 receptor antagonist in mesenchymal stem cell-based tissue repair and regeneration. BioFactors 46:263-275. https://doi.org/10.1002/biof.1587

55. Mehta S, Akhtar S, Porter RM, Önnerford P, Bajpayee AG (2019) Interleukin-1 receptor antagonist (IL-1Ra) is more effective in suppressing cytokine-induced catabolism in cartilage-synovium co-culture than in cartilage monoculture. Arthritis Res Ther 21:238. https://doi.org/10.1186/s13075-019-2003-y

56. Nikfar S, Saiyarsarai P, Tigabu BM, Abdollahi M (2018) Efficacy andsafety of interleukin-1 antagonists in rheumatoid arthritis: asystematic review and meta-analysis. Rheumatol Int 38:13631383. https://doi.org/10.1007/s00296-018-4041-1

57. Mohanty ST, Kottam L, Gambardella A, Nicklin MJ, Coulton L, Hughes D, Wilson AG, Croucher PI, Bellantuono I (2010) Alterations in the self-renewal and differentiation ability of bone marrow mesenchymal stem cells in a mouse model of rheumatoid arthritis. Arthritis Res Ther 12:R149. https://doi.org/10.1186/ar3098

58. Cutolo M (2002) Effects of DMARDs on IL-1Ra levels in rheumatoid arthritis: is there any evidence? Clin Exp Rheumatol 20:S26-31

59. Buchs N, di Giovine FS, Silvestri T, Vannier E, Duff GW, Miossec $P$ (2001) IL-1B and IL-1Ra gene polymorphisms and disease severity in rheumatoid arthritis: interaction with their plasma levels. Genes Immun 2:222-228. https://doi.org/10.1038/sj.gene. 6363766

60. Lee JK, Choi CH (2012) Total knee arthroplasty in rheumatoid arthritis. Knee Surg Relat Res 24:1-6. https://doi.org/10.5792/ ksrr.2012.24.1.1

Publisher's Note Springer Nature remains neutral with regard to jurisdictional claims in published maps and institutional affiliations. 